解 説

$$
\text { ディーゼルエンジン用焼結カムローブ材の開発 }
$$

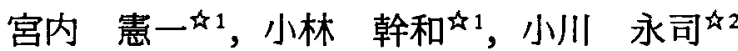

↔1 三菱自動車工業侏トラックバス技術センター，干211-8522 川崎市中原大倉町 10 . ロ 2 日本ビストンリング(侏技術開発第 2 部，干 329-0114 栃木県下都賀郡野木町野木 1111 .

\title{
Development of Sintered Materials for Cam Lobe in Diesel Engine
}

\author{
Kenichi Miyauchi ${ }^{\text {tr1 }}$, Motokazu Kobayashi ${ }^{\text {th1 }}$ and Eiji Ogawa ${ }^{\text {出 } 2}$ \\ $4{ }^{1}$ Mitsubishi Motors Corporation, 10 Ohkubo-cho Nakahara-ku, Kawasaki 211-8522. \\ 4 ${ }^{2}$ Nippon Piston Ring Co., Ltd., 111 Nogi Nogi-machi Shimotsuga-gun, Tochigi 329-0014.
}

Received January 14, 1999

\section{SYNOPSIS}

In order to satisfy the weight and cost reduction of camshaft for trucks and buses, and to improve its wear resistance, it is effective to adopt the composite camshaft which is connected by diffusion-join process between steel shaft and cam lobe. Damage mode between slipper type tappet which is widely adopted for OHV type diesel engines and cam lobe is scuffing and pitting. Thus, it has become necessary to adopt the sintered materials, for cam lobe, which has great resistance to scuffing and pitting. We have developed a Fe based sintered materials for cam lobe to be used together with widely adopted low cost hardened chilled-cast iron tappet. The material for cam lobe has great resistance to scuffing with precipitating of a large quantity of fine $\mathrm{Cr}$-carbide, and has great resistance to pitting with strengthening the matrix by containing a proper amount of $\mathrm{Mo}$ and $\mathrm{Ni}$.

KEY WORDS

composite camshaft, cam lobe, sintered materials, resistance to scuffing, resistance to pitting

\section{1 背景・目的}

トラック・バス用のディーゼルエンジンに対しては, 排ガス 規制対応，高出力化，燃費向上のニースがある.そのため, EGR システムの採用，バルブスプリングカの增大およびカムロー フの狭角化，エンジンオイルの低粘度化等が必要であり，カ ム/タペット間の使用環境はますます過酷となる傾向にある。

トラック・バス用に多く採用されているOHV型ディーゼル エンジン(Fig.1)のテーパカムローブ・球面タペット間は, 滑 りと転がりが混在した接触状況であるため，過酷な使用の場 合スカッフィングおよびビッチングが混在した損傷形態とな る.このようなニースに対応するために，安価な焼入れチル 鋳物夕ペットとの組み合わせに対して耐スカフィング性能お よび耐ピッチング性能に優れた組立式カムシャフト用の鉄系 焼結カムローブ材を開発し実用化した。

\section{2 蟒結材の検討}

カム・タペット間は境界潤滑であるため，双方が直接的に 接触する確率が高くなる．タペットに使用する焼入れチル鋳
物は, マルテンサイトの基地中にセメンタイト $\left(\mathrm{Fe}_{3} \mathrm{C}\right)$ が分散 した組織である.またカムローブ材である鉄系狫結材は，鉄 基地中に炭化物が析出した組織である。したがって，力ム ローブでスカッフィングの発生を抑制するためには，

(1) 非金属同士の接触の確率を高くする: 摺動面表面に炭化物 をできるだけ多量に析出させる。

(2) 基地組織を凝着しにくい組織にする: 基地組織にスカッ フィングが発生しやすい残留オーステナイト(以下的と示 す)量を滅少させる。

が必要である。

また耐ピッチング性能を向上させるためには，

(3) 炭化物の微細化: 炭化物は耐スカッフィング性能に有効で あるが, 勒性が低いためできるだけ小さくする.

(4) 基地組織強化: 基地について, 硬度を高くし疲労強度をあ げるためマルテンサイトまたはべイナイトにする.

が必要である。

以上の点に留意して Table 1 に示すように, $\mathrm{Cr}, \mathrm{Mo}, \mathrm{Ni}$ の添 加量を変化させた供試材料を選定し試験を行なった。 


\section{3 試験方法}

耐スカッフィング性能の評価は，カムシャフトとタペット の実部品を使用しFig.2に示すような試験機で行なった。この 試験機におけるスプリング荷重は980〜3600Nまで自由に設定 可能である. 評価は, カムシャフトを一定時間回転させなか ら,スプリング荷重を低荷重 $(980 \mathrm{~N})$ から，カム・タペット間 にスカッフィングが発生するまで段階的に上昇させ，スカッ フィングが発生した時点でのスプリング荷重を耐スカッフィ ング限界荷重とした (Fig.3).

また耐ビッチング性能の評価は，実機エンジンでジャンピ ングが発生する高回転域を多用し,カムノーズ部付近のカム・ タペット間の接触面圧を過酷にした条件でのファイアリング 耐久試験(実エンジンで実際に燃焼させて行なう耐久試験)で 行なった。

\section{4 試験結果および考察}

試験結果を, Table 1 に示す.

耐スカッフィング性能について, 供試材料 No.1, 3 の耐ス カッフィング限界荷重は $1200 \mathrm{~N}$ と低く，その他の材料のもの は高い。このことから， $\gamma_{R}$ 量か5 $50 \%$ と多い場合は耐スカッ フィング性能は低く，その他の材料のように $\gamma_{\mathrm{R}}$ 量加 $5 \%$ 以下
と少ない場合は，耐スカッフィンク性能は確保されていると いえる. また Cr 量か增加するに伴い析出する炭化物の量仗増

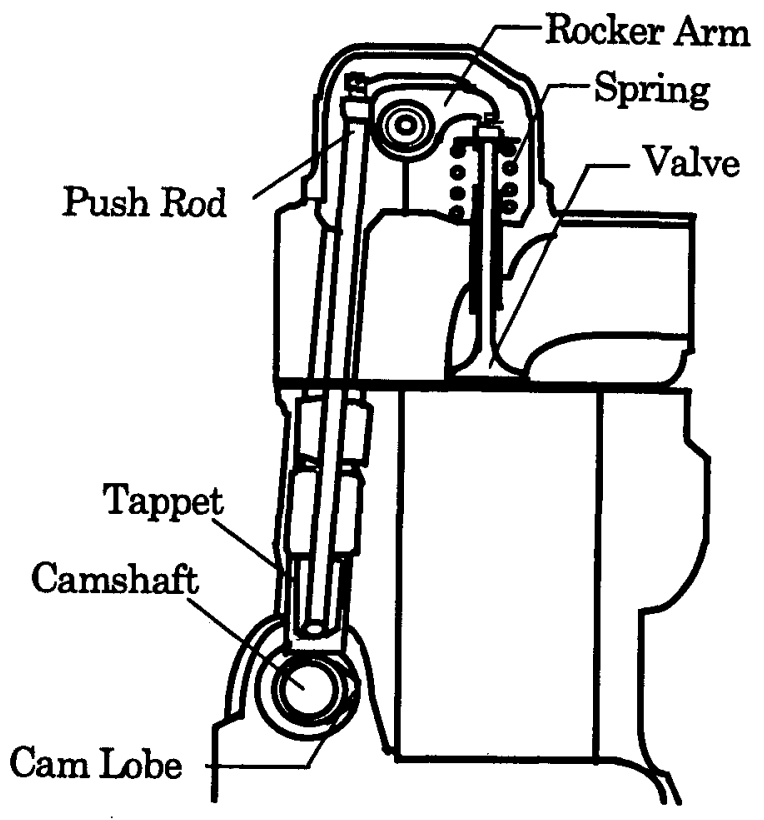

Fig.1 Cross section of valve train.

Table 1 Results of test.

\begin{tabular}{|c|c|c|c|c|c|c|c|}
\hline No. & $\begin{array}{c}\text { Sintered } \\
\text { Materials }\end{array}$ & $\begin{array}{c}\text { Hardness } \\
\text { HRC }\end{array}$ & $\begin{array}{c}\text { Structure } \\
\text { of } \\
\text { Matrix }\end{array}$ & $\begin{array}{c}\text { Size } \\
\text { of } \\
\text { Carbide }\end{array}$ & $\begin{array}{c}\gamma_{\mathrm{R}} \\
\%\end{array}$ & $\begin{array}{c}\text { Scuffing } \\
\text { Limited } \\
\text { Load N }\end{array}$ & $\begin{array}{c}\text { Resistance } \\
\text { to Pitting }\end{array}$ \\
\hline 1 & $4 \mathrm{Cr}-2 \mathrm{Mo}-2 \mathrm{Ni}$ & 56 & $\mathrm{M}+\mathrm{B}+r_{\mathrm{R}}$ & Small & 50 & 1200 & $\mathrm{O}$ \\
\hline 2 & $4 \mathrm{Cr}-1 \mathrm{Mo}-0 \mathrm{Ni}$ & 45 & $\mathrm{P}$ & Coarse & $\leqq 5$ & $\geqq 3600$ & $\times$ \\
\hline 3 & $8 \mathrm{Cr}-2 \mathrm{Mo}-2 \mathrm{Ni}$ & 58 & $\mathrm{M}+\mathrm{B}+r_{\mathrm{R}}$ & Fine & 50 & 1200 & $\mathrm{O}$ \\
\hline 4 & $8 \mathrm{Cr}-2 \mathrm{Mo}-0 \mathrm{Ni}$ & 51 & $\mathrm{P}$ & Fine & $\leqq 5$ & $\geqq 3600$ & $\times$ \\
\hline 5 & $8 \mathrm{Cr}-1 \mathrm{Mo}-0 \mathrm{Ni}$ & 46 & $\mathrm{P}$ & Fine & $\leqq 5$ & $\geqq 3600$ & $\Delta$ \\
\hline 6 & $8 \mathrm{Cr}-2 \mathrm{Mo}-1 \mathrm{Ni}$ & 57 & $\mathrm{M}+\mathrm{B}+r_{\mathrm{R}}$ & Fine & 30 & $\geqq 3600$ & 0 \\
\hline 7 & $10 \mathrm{Cr}-1 \mathrm{Mo}-0 \mathrm{Ni}$ & 50 & $\mathrm{P}$ & Fine & $\leqq 5$ & $\geqq 3600$ & $\times$ \\
\hline 8 & $12 \mathrm{Cr}-1 \mathrm{Mo}-0 \mathrm{Ni}$ & 47 & $\mathrm{P}$ & Fine & $\leqq 5$ & $\geqq 3600$ & $\times$ \\
\hline
\end{tabular}

* $1 \mathrm{M}$ :Martensite B:Bainite $\gamma_{\mathrm{R}}$ :Retained Austenite P:Pearlite

* 2 O:No Pitting $\times$ :Occurrence of Remarkable Pitting $\Delta:$ Occurrence of Minute Pitting 


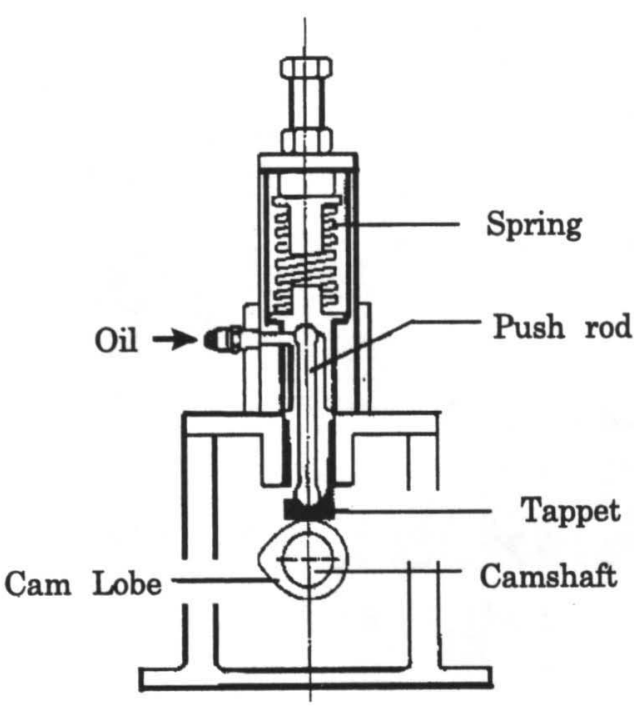

Fig.2 Testing equipment.

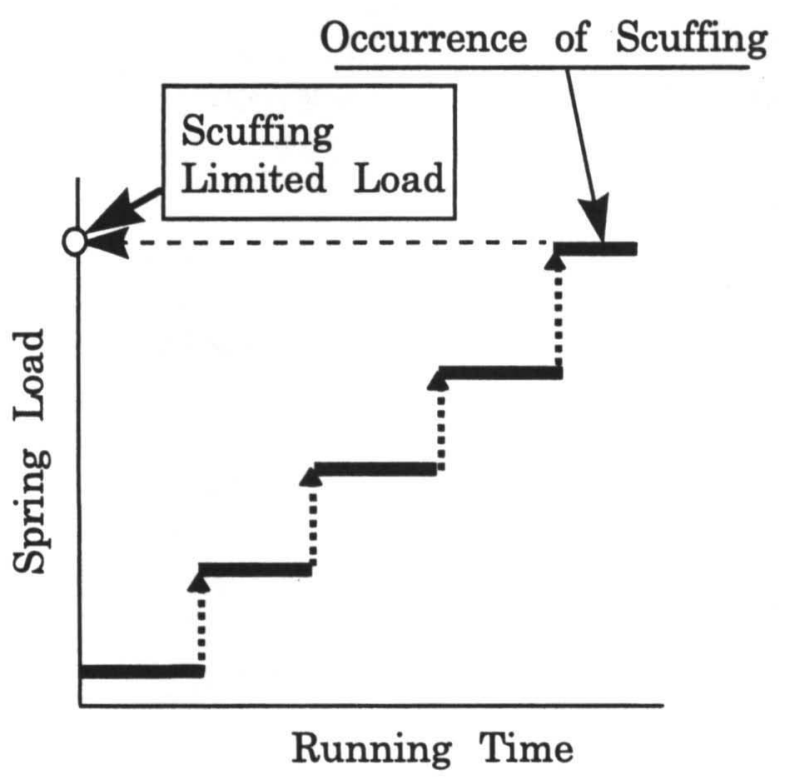

Fig.3 Testing condition.

加し, 耐スカッフィング性能の向上に有利と考える.この点 について $\gamma_{\mathrm{R}}$ 量が少ない供試材料 No.2, 4, 5, 7, 8 で比較すると, 今回の試験条件では耐スカッフィング限界荷重は, 試験機の スプリング荷重設定能力の制約からいずれも $3600 \mathrm{~N}$ 以上とな り, 炭化物量による耐スカッフィング性能の優位差を明確に はできなかった.しかし, 耐スカッフィング限界荷重が3600N であれば実用上問題ない高いレベルである.

耐ピッチング性能について, 供試材料No.1, 3, 6のように基 地組織がマルテンサイトとベイナイトを基本としたものは, 耐ピッチング性能が優れている. しかし供試材料No.2, 4, 5, 7, 8 のように基地組織がパーライトのものは, Fig.4に示すよう にカムノーズ部付近にピッチングが発生した. 以上の結果か ら基地組織の強化は耐ピッチング性能向上に重要であること

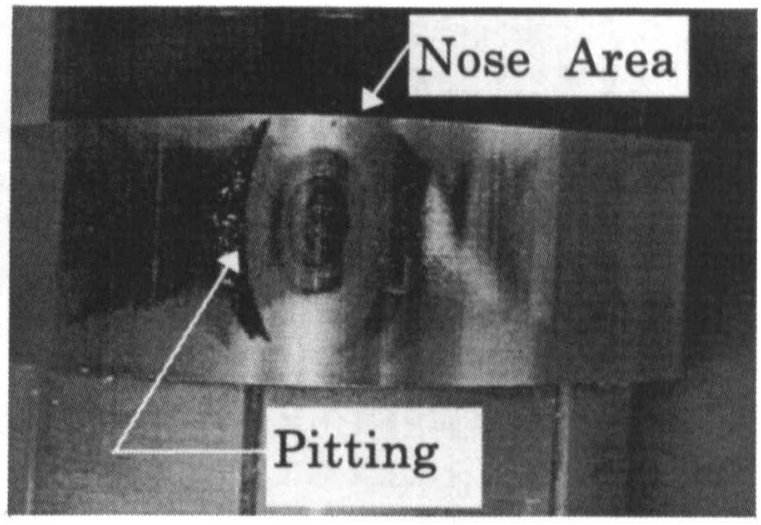

Fig.4 Example of pitting.

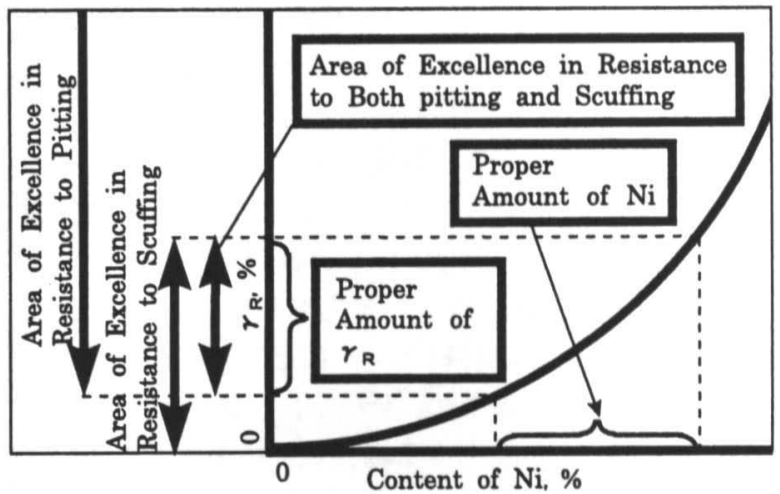

Fig.5 Relation between amount of $\gamma_{\mathrm{R}}$ and content of $\mathrm{Ni}$.

がわかる. また, $\mathrm{Cr}$ 量が増加するに伴って, 炭化物が多量に しかも微細に析出する傾向にある. そこで炭化物の大きさに よる耐ピッチング性能への影響について, 供試材料No.2, 5, 8 の硬さがほぼ同等 (HRC45〜 47), 基地組織がパーライトのも ので比較した。供試材料 $\mathrm{No} .5$ の $8 \% \mathrm{Cr}$ 材はビッチングは軽微 であったが, 粗大な炭化物が析出する供試材料 No. 2 の $4 \% \mathrm{Cr}$ 材だけでなく，かなり微細な炭化物が析出する供試材料No.8 の $12 \% \mathrm{Cr}$ 材でもビッチングが発生し, 炭化物の微細化による 耐ピッチング性能に対する明確な効果を得ることはできな かった.これは, 耐ピッチング性能に及ぼす影響に対しては, 炭化物の大きさの因子よりも, 基地組織の因子の方が大きい ためと考える.

以上の供試材料(No.1 5,7〜8) は, 耐スカッフィング性能, 耐ビッチング性能のどちらか一方のみ優れたもので双方のバ ランスがとれた性能を有したものでない。これらに対し供試 材料No.6は, 耐スカッフィング性能および耐ビッチンク性能 双方に優れている.これは, 耐ビッチング性能については, 基 地組織強化を目的に焼結後の焼入れ性向上に効果がある Mo を $2 \%$ 含有して, 硬さが HRC57 と高く, 基地組織がマルテン サイト+ベイナイトを基本としているためである. また耐ス カッフィンク性能について， $\gamma_{\mathrm{k}}$ 量が50\% と多量の場合には耐 スカッフィング性能に悪影響を及ぼすが, $30 \%$ レベルであれ 
ば問題はないことがわかった.このことから, 耐スカッフィ ング性能に悪影響を及ぼさないような $\gamma_{\mathrm{R}}$ 量の適正な領域があ ると考え，狠量および $\mathrm{Ni}$ 量と耐スカッフィング性能と耐ビッ チング性能との関係について調べた. Fig.5に示すように, ス カッフィングの発生要因となる $\gamma_{\mathrm{R}}$ 量と Ni添加量とは正の関係 があり， $\gamma_{\mathrm{R}}$ 量が約 40\% 以下であれば耐スカッフィンク性能は 確保され，また $\gamma_{\mathrm{R}}$ 量が約 $10 \%$ 以上であれば耐ピッチング性能 は確保されることがわかった.したがって $\gamma_{\mathrm{k}}$ 量 30\%のレベル が, 耐スカッフィング性能と耐ピッチング性能双方が確保さ れる領域であり,このレベルになるようにするためには, $\mathrm{Ni}$ の添加量が $1 \%$ レベルであるといえる. また, 今回の試験で は, 炭化物の量および大きさによる耐スカッフィング性能お よび耐ピッチング性能の優位差を明確にできなかったが, Cr が8\%であれば,炭化物も多量かつ微細であり双方性能に有利 であると考える。

\section{5 開発材組織}

以上の検討結果から, $8 \% \mathrm{Cr}-2 \% \mathrm{Mo}-1 \% \mathrm{Ni}$ の鉄系焼結材を選 定した. 組織を Fig.6に示す. マルテンサイト+ベイナイト $+\gamma_{\mathrm{R}}$ の基地中に, $(\mathrm{Cr}, \mathrm{Mo}, \mathrm{Fe})$ 複合炭化物が析出している. また, 空孔を少なく緻密な焼結材とすることを目的に焼結助剤とし てリンを添加しているため,ステダイトが少量晶出している. 過度にステダイトが晶出する場合は, 相手攻擊性が高くなる が, 開発材は粗大化したステダイトは認められず問題ない。

$$
6 \text { ま と め }
$$

安価なチル鋳物タペットとの組み合わせで耐スカッフィン

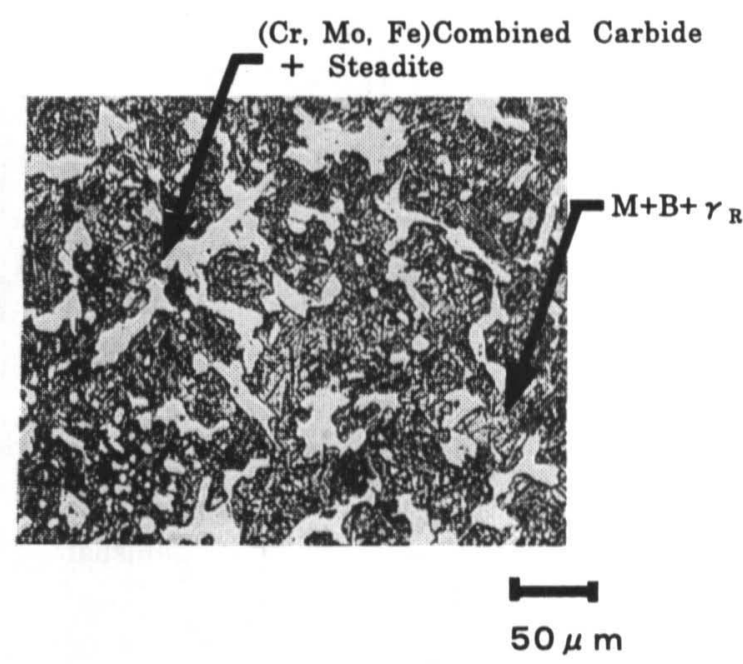

Fig.6 Microstructure of developed hard sintered material.

グおよび耐ビッチング性能に優れた組立式カムシャフトのカ ムローブ用焼結材を以下の点に留意して開発し実用化した. 耐スカッフィング性能および耐ビッチング性能双方に優れた ものとするため,

(1) Cr添加量については, 炭化物を多量・微細化に析出するよ うに $8 \%$ 添加した.

(2) $\mathrm{Ni}$ 添加量については, 耐スカッフィング性能に有害な $\gamma_{R}$ が過利にならない範囲(約30\%)となるように1\%添加した。

(3) Mo 添加量については, 基地組織強化のためにマルテンサ イト+ベイナイトとなるように $2 \%$ 添加した. 